\title{
Profile of copper-associated DNA methylation and its association with incident acute coronary syndrome
}

\author{
Pinpin Long ${ }^{1 \dagger}$, Qiuhong Wang ${ }^{1 \dagger}$, Yizhi Zhang ${ }^{1}$, Xiaoyan Zhu ${ }^{1,2}$, Kuai Yu ${ }^{1}$, Haijing Jiang ${ }^{1}$, Xuezhen Liu ${ }^{1}$, \\ Min Zhou', Yu Yuan', Kang Liu', Jing Jiang ', Xiaomin Zhang ', Meian He' , Huan Guo', Weihong Chen', \\ Jing Yuan', Longxian Cheng ${ }^{3}$, Liming Liang ${ }^{4,5}$ and Tangchun Wu ${ }^{1 *}$ (D)
}

\begin{abstract}
Background: Acute coronary syndrome (ACS) is a cardiac emergency with high mortality. Exposure to high copper (Cu) concentration has been linked to ACS. However, whether DNA methylation contributes to the association between $\mathrm{Cu}$ and ACS is unclear.

Methods: We measured methylation level at > 485,000 cytosine-phosphoguanine sites (CpGs) of blood leukocytes using Human Methylation 450 Bead Chip and conducted a genome-wide meta-analysis of plasma Cu in a total of 1243 Chinese individuals. For plasma Cu-related CpGs, we evaluated their associations with the expression of nearby genes as well as major cardiovascular risk factors. Furthermore, we examined their longitudinal associations with incident ACS in the nested case-control study.

Results: We identified four novel Cu-associated CpGs (cg20995564, cg18608055, cg26470501 and cg05825244) within a 5\% false discovery rate (FDR). DNA methylation level of cg18608055, cg26470501, and cg05825244 also showed significant correlations with expressions of SBNO2, BCL3, and EBF4 gene, respectively. Higher DNA methylation level at cg05825244 locus was associated with lower high-density lipoprotein cholesterol level and higher C-reactive protein level. Furthermore, we demonstrated that higher cg05825244 methylation level was associated with increased risk of ACS (odds ratio [OR], 1.23; 95\% Cl 1.02-1.48; $P=0.03$ ).

Conclusions: We identified novel DNA methylation alterations associated with plasma $\mathrm{Cu}$ in Chinese populations and linked these loci to risk of ACS, providing new insights into the regulation of gene expression by Cu-related DNA methylation and suggesting a role for DNA methylation in the association between copper and ACS.
\end{abstract}

Keywords: Copper, DNA methylation, Acute coronary syndrome, Gene expression

*Correspondence: wut@mails.tjmu.edu.cn

tPinpin Long and Qiuhong Wang have contributed equally to the study

' Department of Occupational and Environmental Health, Key Laboratory

of Environment and Health, Ministry of Education and State Key

Laboratory of Environmental Health (Incubating), School of Public Health,

Tongji Medical College, Huazhong University of Science and Technology,

13 Hangkong Rd., Wuhan 430030, Hubei, China

Full list of author information is available at the end of the article

\section{Introduction}

Copper $(\mathrm{Cu})$ is an essential metal for the human body and involves in the regulation of biological metabolism and enzyme synthesis, whereas excessive $\mathrm{Cu}$ can also be detrimental to human health [1]. Epidemiological studies have shown that exposure to high copper concentration was associated with an increased risk of cardiovascular disease (CVD) [2-4]. Acute coronary syndrome (ACS) is a severe CVD subtype with high mortality, including original author(s) and the source, provide a link to the Creative Commons licence, and indicate if changes were made. The images or other third party material in this article are included in the article's Creative Commons licence, unless indicated otherwise in a credit line to the material. If material is not included in the article's Creative Commons licence and your intended use is not permitted by statutory regulation or exceeds the permitted use, you will need to obtain permission directly from the copyright holder. To view a copy of this licence, visit http://creativecommons.org/licenses/by/4.0/. The Creative Commons Public Domain Dedication waiver (http://creativeco mmons.org/publicdomain/zero/1.0/) applies to the data made available in this article, unless otherwise stated in a credit line to the data. 
acute myocardial infarction (AMI) and unstable angina (UA). A previous meta-analysis of 19 case-control studies showed a significant positive association between high serum $\mathrm{Cu}$ level and myocardial infarction [5]. In a prospective cohort study of 1666 participants in eastern Finland, researchers observed that serum copper concentration in the two highest tertiles associated with 3.5-fold and 4.0-fold risk of AMI [6]. Although the underlying mechanisms between high copper status and risk of ACS were not fully understood, accumulating evidence indicated that $\mathrm{Cu}$ exposure can cause the production of oxidative stress products (including reactive oxygen species) [7, 8], pro-inflammatory factors [9], abnormal blood lipid metabolism [10], and endothelial cell damage [11].

DNA methylation is a process by which methyl groups are added to the DNA molecule without altering the primary DNA sequence [12]. It is believed that DNA methylation can participate in multiple cellular, physiological, biochemical, and pathological processes by regulating gene expression and genomic stability [13]. DNA methylation has been associated with a range of adverse health outcomes, including ACS [14], cancer [15], diabetes [16], and neurodegenerative diseases [17]. Furthermore, DNA methylation is the most well-studied epigenetic regulatory factor related to metal exposure, and previous studies have suggested that methylation changes related to metal exposure may provide key insights into disease development and susceptibility [18-21]. For example, Everson et al. demonstrated that cadmium-associated differential methylation may be a potentially novel mechanism for adverse effects of prenatal cadmium on the offspring [18]. A recent study has found that mercuryassociated alterations in methylation were associated with adverse neurological outcomes [19]. Ren et al. [20] have reviewed that alteration in methylation may mediate the toxicity and carcinogenicity caused by arsenic exposure.

DNA methylation may also be one of the important mechanisms by which $\mathrm{Cu}$ exposure exerts its biological effects on ACS. Investigating DNA methylation alterations related to $\mathrm{Cu}$ is important to understand the metabolism and pathogenesis of copper. A study comprising 126 elder individuals indicated that the daily intake of $\mathrm{Cu}$ had a negative correlation with the global DNA methylation profile of leukocytes [22]. To date, only one genomewide DNA methylation study has been conducted to investigate associations between placental $\mathrm{Cu}$ and DNA methylation alterations in humans, and they observed nine $\mathrm{Cu}$-associated differentially methylated regions (DMRs) and 15 suggestive cytosine-phosphoguanine sites (CpGs) $\left(p\right.$ Values $\left.<1 \times 10^{-5}\right)$ [23]. So far, no studies have been conducted to identify gene-specific epigenetic alterations related to plasma $\mathrm{Cu}$ in middle-aged and elderly populations and investigate their relations to risk of ACS. To fill a gap in this field, we performed an epigenome-wide association study (EWAS) of plasma $\mathrm{Cu}$ across five Chinese panels and assessed the association of findings with gene expressions, cardiovascular risk factors and incident ACS.

\section{Materials and methods \\ Study design and participants}

We conducted a genome-wide meta-analysis of DNA methylation and plasma $\mathrm{Cu}$ concentrations across five panels in Chinese populations, four of which have been described in detail previously $[24,25]$. The detailed description of the study population was shown in Additional file 1: Method S1.

Briefly, a nested case-control study was conducted by randomly selected 344 incident ACS cases and 344 controls matched for age ( \pm 3 years), sex, and sampling time at baseline ( \pm 40 days), based on baseline and the first follow-up of the Dongfeng-Tongji (DFTJ) cohort, a prospective cohort recruited retired workers from Dongfeng Motor Corporation (DMC) in Shiyan City, Hubei Province, China [26]. Totally, 688 individuals were included in this study as DFTJ panel. The ascertainment criteria for incident ACS were the first occurrence of unstable angina (UA), non-ST-segment elevation myocardial infarction (NSTEMI), or STEMI during follow-up [27]. ACS was confirmed and classified according to the diagnostic criteria of AHA and WHO [28-30] and finally diagnosed by professional physicians.

A two-stage genome-wide methylation association analysis was performed to identify the DNA methylation alterations associated with prevalent ACS [25]. This study included 103 prevalent ACS patients in Wuhan (ACSWH panel) and 103 prevalent ACS patients in Zhuhai (ACS-GD panel). A total of 283 controls for the prevalent ACS patients were selected from the Wuhan-Zhuhai (WHZH) cohort, a cohort recruited community residents (18-80 years old) lived in Wuhan or Zhuhai city for over 5 years [31]. These individuals were included in our study as WHZH panel.

A total of 144 healthy individuals who had regular physical examinations at the Health Examination Center of Dongfeng Central Hospital (Dongfeng Motor Corporation and Hubei University of Medicine) in Shiyan were recruited to investigate whether DNA methylation was associated with gene expression. These individuals were included in our study as SY panel.

Each panel of our study has been approved by the Ethics and Human Subject Committees of Tongji Medical College. All participants agreed to participate in this study and signed the written informed consent. 


\section{Copper assessment}

Peripheral blood samples of participants were collected in EDTA vacuum blood collection tubes after overnight fasting. Plasma was separated from blood cells by centrifugation and stored at $-80{ }^{\circ} \mathrm{C}$ within $2 \mathrm{~h}$. The concentrations of plasma $\mathrm{Cu}$ were measured by Agilent $7700 \times$ inductively coupled plasma mass spectrometer (ICP-MS) after randomization, based on the methods described previously [3, 32]. A metal variability study consisted of 138 healthy participants from the DFTJ cohort was conducted previously to ensure the reproducibility of metals by comparing plasma metal concentrations at baseline and the first follow-up [32], and the intraclass correlation coefficient (ICC) for plasma $\mathrm{Cu}$ was 0.74 ( $p$ Value $<0.001$ ), which indicates favorable reproducibility. Six samples from the DFTJ panel, twelve samples from the ACS-WH panel, two samples from the ACS-GD panel, thirty-four samples from the WHZH panel and one sample from the SY panel with non-available $\mathrm{Cu}$ concentrations were excluded from the study. Assessment of other covariates see Additional file 1: Method S2.

\section{DNA methylation and gene expression}

Genome-wide DNA methylation assays for participants from the five panels and gene expression assays for the SY panel were conducted with the same protocol described previously [25]. Infinium HumanMethylation450 BeadChip (Illumina) was used to quantify DNA methylation at $>485,000$ cytosine-phosphoguanine sites (CpGs) with genomic DNA extracted from whole blood of all the participants after randomization. After quality controls and normalization, 688 participants from the DFTJ panel, 102 participants from ACS-WH, 100 participants from ACSGD, 264 participants from the WHZH panel, and 144 participants from the SY panel were retained.

HumanHT-12 version 4 Expression BeadChip (Illumina) was used to perform gene expression profiles by a commercial company (ETMD, Beijing, China) with total RNA isolated from blood leukocytes. For detailed information of experimental procedures, quality control methods, and normalization see Additional file 1: Method S3.

\section{Statistical analyses}

\section{Genome-wide analysis of DNA methylation with plasma $\mathrm{Cu}$}

We employed SmartSVA, a more efficient version of surrogate variable analysis (SVA), to control the potential confounding caused by cell mixtures and unknown variations in the genome-wide methylation analyses [33]. Surrogate variables (SVs) were generated from SmartSVA using variables including inverse normal transformed
$\mathrm{Cu}$ (INT-Cu) concentration, age, sex, body mass index (BMI), smoking status, drinking status, and the proportions of major leukocytes. For the DFTJ panel and the SY panel, cellular proportions included proportions of neutrophils, lymphocytes, monocytes, eosinophils, and basophils, while for the other three panels this included proportions of neutrophils, lymphocytes, and intermediate cells (sum of monocytes, eosinophils, and basophils). To explore the associations between $\mathrm{Cu}$ level and CpGs, we first conducted linear regression models in five panels, separately. In each model, variables used in SmartSVA and SVs were included as covariates and INT-methylation values were included as dependent variable. Finally, we performed a fixed-effect meta-analysis to combine the association results of all the five panels, meta $\mathrm{Z}$ scores and $p$ values were obtained by weighted sum-ofz-scores method in R 3.1.2 (R Core Team 2014). Statistical significance was determined as false discovery rate $(F D R)<0.05$. Manhattan and QQ plots were produced using the "qqman" package to visualize the genomic distribution of significant associations. Genomic inflation lambda $(\lambda)$ was calculated in R 3.1.2 (R Core Team 2014) to quantify the statistical inflation of $p$ values. Regional association plot of $\mathrm{Cu}$-associated $\mathrm{CpGs}$ was generated using "coMET" package [34], and correlation matrix of CPG sites in the region was assessed by Spearman correlation test.

\section{Correlations between $C p G s$ and gene expression level}

Linear regression analysis was performed to estimate the correlations between methylation and gene expression using INT-expression values as dependent variables, and independent variables including age, sex, and methylation values without transformation. For each pair of methylation-expression probes, the significant threshold was set at $F D R<0.05$. In addition, we searched the public database for more DNA methylation-expression associations (https://www.genenetwork.nl/biosqtlbrowser/) [35]. We used gene set enrichment analysis to examine the Kyoto Encyclopedia of Genes and Genomes (KEGG) pathways associated with genes annotated to the top 500 $\mathrm{Cu}$-related CpG sites [36].

\section{Associations of Cu-related methylation with cardiovascular risk factors}

We conducted meta-analyses to investigate the association of four $\mathrm{Cu}$-related $\mathrm{CpGs}$ with cardiovascular risk factors in the DFTJ panel, the WHZH panel, and the SY panel. In each panel, cardiovascular risk factors include BMI, systolic blood pressure (SBP), diastolic blood pressure (DBP), high-density lipoprotein cholesterol (HDL-C), low-density lipoprotein cholesterol (LDL-C), triglyceride (TG), fasting glucose (FG) and C-reactive 
protein (CRP), and covariates included age, sex, BMI, smoking status, and drinking status, while in the DFTJ panel we additionally adjusted for incident ACS indicator.

\section{Associations of Cu-related methylation with incident ACS}

To explore the association of $\mathrm{Cu}$-related $\mathrm{CpGs}$ with incident ACS in the DFTJ panel, unconditional logistic regression models were used by including quartiles of INT-DNA methylation and continuous INT-DNA methylation values as independent variables in the model, respectively. Potential covariates in the first model including age and sex, further adjustments in the second model including BMI, smoking status, drinking status, diabetes, hypertension, and hyperlipidemia. Covariates adjusted in the second model are presented in Additional file 2: Table S1.

\section{Results}

Basic characteristics of the study participants

Table 1 summarizes the characteristics and plasma copper concentrations of participants by five panels. After excluding samples with failed copper detection and failed methylation quality control, a total of 1243 participants were recruited in the genome-wide meta-analysis, including 682 participants from the DFTJ cohort (male: 52.1\%; mean age: 65.2 years), 90 ACS patients from Wuhan (male: $82.2 \%$; mean age: 59.3 years), 98 ACS patients from Guangdong (male: $79.6 \%$; mean age: 59.3 years), 230 community residents from the WHZH cohort (male: 79.1\%; mean age: 54.5 years), and 143 healthy participants from Shiyan (male: $74.1 \%$; mean age: 41.4 years). The flowchart of the study is shown in Additional file 3: Figure S1. The

Table 1 Basic characteristics and plasma copper concentrations of the study participants

\begin{tabular}{|c|c|c|c|c|c|}
\hline Characteristics $^{a}$ & DFTJ $(n=682)$ & ACS-WH $(n=90)$ & ACS-GD $(n=98)$ & WHZH $(n=230)$ & $\begin{array}{l}\text { SY } \\
(n=143)\end{array}$ \\
\hline Age, years & $65.2 \pm 6.3$ & $59.3 \pm 10.0$ & $59.3 \pm 11.4$ & $54.5 \pm 13.2$ & $41.4 \pm 10.2$ \\
\hline Male, $n(\%)$ & $355(52.1)$ & $74(82.2)$ & $78(79.6)$ & $182(79.1)$ & $106(74.1)$ \\
\hline \multicolumn{6}{|l|}{ Smoking status, $n(\%)$} \\
\hline Current smoker & $160(23.5)$ & $33(36.7)$ & $41(41.8)$ & $95(41.3)$ & $45(31.5)$ \\
\hline Former smoker & $85(12.5)$ & $23(25.6)$ & $13(13.3)$ & $23(10.0)$ & $2(1.4)$ \\
\hline Never smoker & $437(64.1)$ & $34(37.8)$ & $44(44.9)$ & $112(48.7)$ & $96(67.1)$ \\
\hline \multicolumn{6}{|l|}{ Drinking status, $n$ (\%) } \\
\hline Current drinker & $164(24.0)$ & $21(23.3)$ & $20(20.4)$ & $65(28.3)$ & $54(37.8)$ \\
\hline Former drinker & $30(4.4)$ & $0(0.0)$ & $0(0.0)$ & $5(2.2)$ & $1(0.7)$ \\
\hline Never drinker & $488(71.6)$ & $69(76.7)$ & $78(79.6)$ & $160(69.6)$ & $88(61.5)$ \\
\hline $\mathrm{BMI}, \mathrm{kg} / \mathrm{m}^{2}$ & $24.9 \pm 3.2$ & $24.8 \pm 2.8$ & $23.0 \pm 2.4$ & $23.2 \pm 2.6$ & $24.2 \pm 2.7$ \\
\hline Systolic blood pressure, mmHg & $128.9 \pm 17.1$ & $129.9 \pm 20.5$ & $134.5 \pm 25.3$ & $129.1 \pm 16.7$ & $130.7 \pm 18.1$ \\
\hline Diastolic blood pressure, $\mathrm{mmHg}$ & $75.4 \pm 10.3$ & $81.2 \pm 13.4$ & $79.1 \pm 13.8$ & $76.9 \pm 9.8$ & $80.2 \pm 12.1$ \\
\hline Fasting glucose, $\mathrm{mmol} / \mathrm{L}$ & $6.1 \pm 1.6$ & $5.3 \pm 0.8$ & $6.9 \pm 1.7$ & $4.7 \pm 1.3$ & $5.5 \pm 0.7$ \\
\hline Triglyceride, mmol/L & $1.5 \pm 1.0$ & $1.7 \pm 1.1$ & $1.5 \pm 1.0$ & $1.4 \pm 1.0$ & $1.4 \pm 1.0$ \\
\hline Total cholesterol, mmol/L & $5.3 \pm 0.9$ & $3.9 \pm 1.0$ & $4.9 \pm 1.2$ & $5.1 \pm 1.1$ & $4.9 \pm 0.8$ \\
\hline $\mathrm{HDL}-\mathrm{C}, \mathrm{mmol} / \mathrm{L}$ & $1.4 \pm 0.3$ & $1.1 \pm 0.3$ & $1.2 \pm 0.2$ & $1.5 \pm 0.4$ & $1.4 \pm 0.3$ \\
\hline LDL-C, mmol/L & $3.1 \pm 0.8$ & $2.1 \pm 0.8$ & $3.1 \pm 0.9$ & $3.0 \pm 1.0$ & $2.9 \pm 0.7$ \\
\hline \multicolumn{6}{|l|}{ Major leukocyte compositions } \\
\hline Basophil proportion, \% & $1.3 \pm 0.4$ & - & - & - & $1.3 \pm 1.2$ \\
\hline Eosinophil proportion, \% & $2.2 \pm 1.6$ & - & - & - & $2.1 \pm 1.6$ \\
\hline Monocyte proportion, \% & $7.3 \pm 1.7$ & - & - & - & $4.9 \pm 2.7$ \\
\hline Lymphocyte proportion, \% & $32.8 \pm 8.6$ & $28.3 \pm 9.9$ & $19.5 \pm 11.9$ & $38.0 \pm 8.2$ & $33.6 \pm 7.5$ \\
\hline Neutrophil proportion, \% & $57.0 \pm 9.0$ & $62.6 \pm 10.4$ & $72.3 \pm 13.4$ & $55.3 \pm 8.4$ & $58.0 \pm 8.2$ \\
\hline Intermediate cells proportionº $\%$ & $10.7 \pm 10.7$ & $9.1 \pm 3.1$ & $8.2 \pm 4.0$ & $6.8 \pm 3.7$ & $8.3 \pm 2.7$ \\
\hline C-reactive protein, $\mathrm{mg} / \mathrm{L}$ & $2.5 \pm 4.3$ & - & - & $1.6 \pm 3.7$ & $0.8 \pm 1.3$ \\
\hline Plasma copper $(\mu \mathrm{g} / \mathrm{L})$ & $951.5 \pm 178.6$ & $812.0 \pm 183.5$ & $897.7 \pm 495.5$ & $899.7 \pm 194.3$ & $782.5 \pm 141.7$ \\
\hline
\end{tabular}

DFTJ the Dongfeng-Tongji Cohort, ACS-WH ACS patients recruited in Wuhan, ACS-GD ACS patients recruited in Zhuhai, WHZH participants from the Wuhan-Zhuhai cohort, SY healthy individuals from Shiyan, China

a The continuous variables are presented as mean \pm SD. Categorical variables are presented as $n$ (\%)

b Intermediate cells consist of monocytes, eosinophils, and basophils 
mean $\mathrm{Cu}$ concentrations were 951.5, 812.0, 897.7, 899.7, and $782.5 \mu \mathrm{g} / \mathrm{L}$ for the DFTJ panel, ACS-WH, ACS-GD, the WHZH panel, and the SY panel, respectively. The distribution of plasma $\mathrm{Cu}$ concentrations in each panel is shown in Additional file 3: Figure S2.

\section{Genome-wide analysis of DNA methylation and plasma copper}

The genome-wide meta-analysis identified 4 CpGs significantly associated with plasma $\mathrm{Cu}$ concentration with an $F D R<0.05$ and additional 12 CpGs with $p$ Values $<1 \times 10^{-5}$ (Table 2, Fig. 1), and the results of associations between DNA methylation and plasma $\mathrm{Cu}$ in each panel are presented in Additional file 2: Table S2. Of the top four hits, plasma $\mathrm{Cu}$ was significantly associated with cg20995564 on the body of $Z E B 2$ gene (meta $Z=-5.52$; $p$ Values $\left.=3.41 \times 10^{-8}\right), \quad \operatorname{cg} 18608055$ on the body of SBNO2 gene (meta $Z=-5.30 ; p$ Values $=1.13 \times 10^{-7}$ ), cg26470501 on the body of BCL3 gene (meta $Z=-5.24$; $p$ Values $=1.63 \times 10^{-7}$ ), and $\operatorname{cg} 05825244$ on the body of EBF4 gene (meta $\mathrm{Z}=5.30 ; p$ Values $=1.14 \times 10^{-7}$ ).

More than one differentially methylated loci with $p$ Values $<1 \times 10^{-5}$ in EBF4 gene were observed (cg05825244 at chr20:2730488 and cg24263062 at chr20:2730191). The Manhattan plot of $\mathrm{Cu}$ meta-analysis results surrounding the EBF4 gene exhibited a strong comethylation structure that can be shown with strong Spearman correlation $p$ values (Additional file 3: Figure S3).

\section{Correlations with the expression of annotated genes}

We examined whether there were correlations between methylation level at the top $16 \mathrm{Cu}$-related $\mathrm{CpGs}$ and gene expression level in the SY panel. A total of 34 CpG-expression probe pairs annotated to 24 genes with expression rates $>30 \%$ were presented, and methylation level at $4 \mathrm{CpG}$ was significantly correlated with the expression level of annotated genes with $F D R<0.05$ (Table 3). We additionally found two CpGs (cg26470501 and cg24263062) that were strongly associated with annotated gene expression in the public database. The genes annotated to the top $500 \mathrm{Cu}$-related $\mathrm{CpG}$ sites were enriched in five significant $K E G G$ pathways $(F D R<0.01)$, including insulin signaling pathway, type 2 diabetes mellitus, amyotrophic lateral sclerosis, calcium signaling pathway, and purine metabolism (Additional file 2: Table S3).

\section{Relations to the cardiovascular risk factors}

We tested the associations of four $\mathrm{Cu}$-related $\mathrm{CpGs}$ $(F D R<0.05)$ with cardiovascular risk factors in participants who were not currently ACS patients. Methylation level of cg05825244 presented significant correlations

Table 2 Sixteen CpGs associated with plasma copper in the genome-wide meta-analysis ( $p$ Value $<1 \times 10^{-5}$ )

\begin{tabular}{|c|c|c|c|c|c|c|c|}
\hline \multirow[t]{2}{*}{ CpG } & \multirow[t]{2}{*}{ Chr } & \multirow[t]{2}{*}{ Position } & \multirow[t]{2}{*}{ Gene } & \multirow[t]{2}{*}{ Relation to gene } & \multicolumn{3}{|c|}{$\begin{array}{l}\text { Genome-wide meta-analysis } \\
\text { of DNA methylation and plasma }_{\text {copper }}{ }^{\mathrm{a}}\end{array}$} \\
\hline & & & & & Meta Z & $p$ Value & FDR \\
\hline $\operatorname{cg} 25112191$ & 1 & 151804260 & RORC; KIAA1026; TDRKH & 1stExon, 5'UTR; $<50 \mathrm{~kb} ;<50 \mathrm{~kb}$ & -4.89 & $9.96 \times 10^{-7}$ & 0.09 \\
\hline $\operatorname{cg} 11023668$ & 2 & 25095040 & $A D C Y 3$ & Body & -4.45 & $8.68 \times 10^{-6}$ & 0.23 \\
\hline cg20995564 & 2 & 145172035 & ZEB2 & Body & -5.52 & $3.41 \times 10^{-8}$ & 0.01 \\
\hline cg09480515 & 2 & 237033375 & $A G A P 1 ; G B X 2$ & $3^{\prime} \cup T R ;<50 \mathrm{~kb}$ & -4.47 & $7.75 \times 10^{-6}$ & 0.22 \\
\hline $\operatorname{cg} 21945842$ & 3 & 105084992 & ALCAM & TSS1500 & -4.51 & $6.48 \times 10^{-6}$ & 0.22 \\
\hline $\operatorname{cg} 24805089$ & 5 & 176860947 & $\begin{array}{l}\text { GRK6; DBN1; F12; PDLIM7; SLC34A1; } \\
\text { PFN3;PRR7 }\end{array}$ & $\begin{array}{l}\text { Body } ;<50 \mathrm{~kb} ;<50 \mathrm{~kb} ;<50 \mathrm{~kb} ;<50 \\
\text { kb; }<50 \mathrm{~kb} ;<50 \mathrm{~kb}\end{array}$ & -4.55 & $5.39 \times 10^{-6}$ & 0.22 \\
\hline $\operatorname{cg} 21852842$ & 7 & 1896827 & MAD1L1 & Body & -4.55 & $5.47 \times 10^{-6}$ & 0.22 \\
\hline cg18734877 & 8 & 27297419 & PTK2B; CHRNA2; EPHX2 & Body $;<50 \mathrm{~kb} ;<50 \mathrm{~kb}$ & -4.52 & $6.33 \times 10^{-6}$ & 0.22 \\
\hline cg07798295 & 16 & 89715839 & CHMP1A & Body & -4.80 & $1.61 \times 10^{-6}$ & 0.12 \\
\hline $\operatorname{cg} 18608055$ & 19 & 1130866 & SBNO2; GPX4; HMHA1 & Body $;<50 \mathrm{~kb} ;<50 \mathrm{~kb}$ & -5.30 & $1.13 \times 10^{-7}$ & 0.02 \\
\hline $\operatorname{cg} 26470501$ & 19 & 45252955 & $B C L 3$ & Body & -5.24 & $1.63 \times 10^{-7}$ & 0.02 \\
\hline $\operatorname{cg} 24263062$ & 20 & 2730191 & EBF4; CPXM1 & Body $;<50 \mathrm{~kb}$ & 4.48 & $7.30 \times 10^{-6}$ & 0.22 \\
\hline $\operatorname{cg} 05825244$ & 20 & 2730488 & $E B F 4 ; C P X M 1$ & Body $;<50 \mathrm{~kb}$ & 5.30 & $1.14 \times 10^{-7}$ & 0.02 \\
\hline $\operatorname{cg} 01523712$ & 20 & 43437858 & RIMS4 & Body & 4.63 & $3.67 \times 10^{-6}$ & 0.22 \\
\hline cg09349128 & 22 & 50327986 & ZBED4; ALG12; CRELD2; PIM3 & $<50 \mathrm{~kb} ;<50 \mathrm{~kb} ;<50 \mathrm{~kb} ;<50 \mathrm{~kb}$ & -4.59 & $4.41 \times 10^{-6}$ & 0.22 \\
\hline cg15376401 & $x$ & 73438975 & NCRNA00182; MIR374B; MIR421 & Body; TSS1500; TSS1500 & 4.47 & $7.73 \times 10^{-6}$ & 0.22 \\
\hline
\end{tabular}

Body gene body, Chr Chromosome, FDR false discovery rate, $<50 \mathrm{~kb}$ within 50,000 bps of a candidate CpG site, UTR untranslated regions

a Fixed effect meta-analysis was used with a weighted sum-of-z-scores method to obtain the meta Z score and $p$ Values. The significant threshold of genome-wide meta-analysis of DNA methylation and plasma copper was set at $F D R<0.05$ 


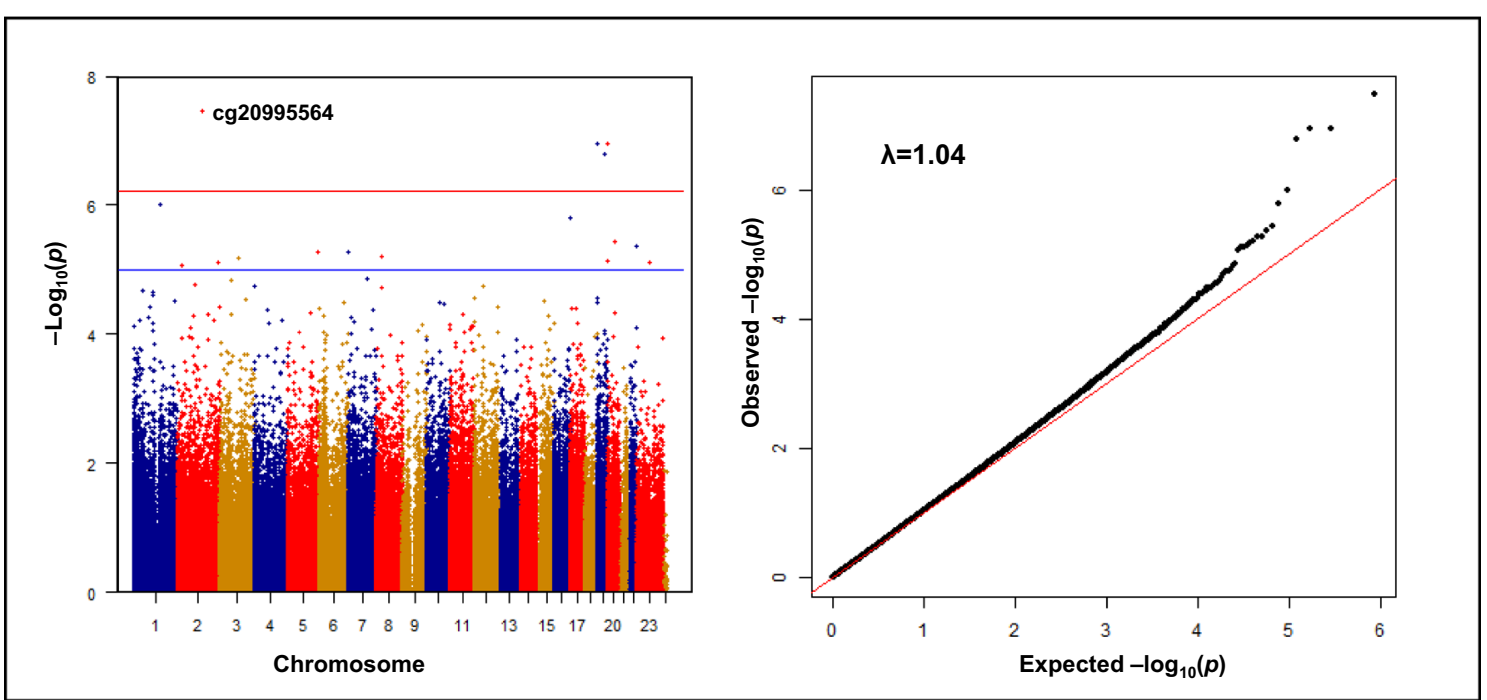

Fig. 1 Manhattan plot and Q-Q plot for epigenome-wide association results for plasma copper concentration. The $x$-axis indicates genomic locations of the $\mathrm{CpGs}$, the $y$-axis indicates $-\log 10$ ( $p$ Value) of the associations. The horizontal red line corresponds to the false discovery rate $(F D R)=0.05$ threshold; the horizontal blue line represents suggestive association ( $p$ Value $<1 \times 10^{-5}$ ). In the Q-Q plot, the $x$-axis shows the expected $-\log 10$ ( $p$ Value), whereas the $y$-axis indicates the observed $-\log 10$ ( $p$ Value)

with serum HDL-C level $(p$ Value $=0.005)$ and CRP level $(p$ Value $=0.03)$, we also observed a significant correlation between methylation level of cg26470501 and serum CRP level ( $p$ Value $=0.003$, Additional file 2: Table S4). We did not find other risk factors associated with $\mathrm{Cu}$ related CpGs.

\section{Associations of Cu-related CpGs with incident ACS}

We examined the associations of $\mathrm{Cu}$-related $\mathrm{CpGs}$ with incident ACS in the nested case-control participants within DFTJ cohort and observed that higher methylation level at cg05825244 locus was associated with an increased risk of ACS: The OR (95\% CI) compared the fourth quartile with the first quartile was 1.78 (1.07, 2.98; $p$-Trend $=0.04)$, and for linear model, the OR $(95 \% \mathrm{CI})$ was $1.23(1.02,1.48 ; p$-Linearity $=0.03)$ according to per INT-DNA methylation values increase (Table 4).

\section{Discussion}

We integrated genome-wide DNA methylation and gene expression profiles in leukocyte of 1243 Chinese individuals to examine the gene-specific DNA methylation changes associated with $\mathrm{Cu}$ concentration and explore the functional consequences by assessing gene expression and clinical outcomes associated with identified CpGs. We observed four novel methylation loci in $Z E B 2$, $S B N O 2, B C L 3$, and EBF4 that were strongly associated with $\mathrm{Cu}$ exposure $(F D R<0.05)$ and additional $12 \mathrm{CpGs}$ with suggestive associations ( $p$ Value $<1 \times 10^{-5}$ ). Three of the four identified CpGs showed lower methylation level in association with higher $\mathrm{Cu}$ exposure. In addition, we observed that several of the differentially methylated loci related to plasma $\mathrm{Cu}$ were associated with corresponding gene expression level, indicating that copper may regulate gene expression by altering DNA methylation level. We also demonstrated that the DNA methylation level at cg05825244 was associated with lower HDL-C level and higher CRP level. Most notably, we observed that methylation alteration of cg05825244 was statistically significantly associated with increased risk of ACS.

Copper is an essential but toxic trace element for the human body and the major dietary sources of copper are legumes, potato, nuts, and beef [37]. Previous metal variability study has shown that plasma copper is a reliable biomarker reflecting chronic copper exposure with an ICC of 0.74 over five years [32]. A recent meta-analysis revealed that exposure to $\mathrm{Cu}$ was associated with increased risk of CVD and CHD by comparing top versus bottom thirds of baseline level [4]. A prospective study consisting of 1666 men in Eastern Finland demonstrated that high copper status was an independent risk factor for acute myocardial infarction (AMI), with an average copper level of $1110 \mu \mathrm{g} / \mathrm{L}$ in participants [6]. Xiao et al. [3] reported that elevated plasma copper concentrations were associated with a higher risk of stroke in a linear 
Table 3 Methylation-gene expression correlations of the plasma copper-related CpGs ( $p$ Value $<1 \times 10^{-5}$ )

\begin{tabular}{|c|c|c|c|c|c|c|c|c|}
\hline \multicolumn{2}{|c|}{ CpGs } & \multicolumn{3}{|c|}{ Gene expression probes } & \multicolumn{4}{|c|}{ Methylation-expression correlations } \\
\hline CHR & CpG & Expression probe & Gene & Expression rate & Relation to gene & Effect & $p$-Value & $F D R$ \\
\hline 1 & $\operatorname{cg} 25112191$ & ILMN_1771126 & $R O R C$ & $51.39 \%$ & 1stExon;5'UTR & $1.67(3.01)$ & 0.58 & 0.76 \\
\hline 1 & $\operatorname{cg} 25112191$ & ILMN_1734366 & $R O R C$ & $84.72 \%$ & 1stExon;5'UTR & $1.64(2.22)$ & 0.74 & 0.84 \\
\hline 1 & $\operatorname{cg} 25112191$ & ILMN_1680399 & KIAA1026 & $65.28 \%$ & $<50 \mathrm{~kb}$ & $-7.51(2.20)$ & $9.83 \times 10^{-4}$ & $3.71 \times 10^{-3}$ \\
\hline 1 & cg25112191 & ILMN_1770927 & KIAA1026 & $87.50 \%$ & $<50 \mathrm{~kb}$ & $-7.43(2.05)$ & $4.33 \times 10^{-4}$ & $1.84 \times 10^{-3}$ \\
\hline 1 & $\operatorname{cg} 25112191$ & ILMN_1798458 & KIAA1026 & $95.83 \%$ & $<50 \mathrm{~kb}$ & $-7.19(1.98)$ & $3.91 \times 10^{-4}$ & $2.22 \times 10^{-3}$ \\
\hline 1 & cg25112191 & ILMN_1792726 & TDRKH & $36.81 \%$ & $<50 \mathrm{~kb}$ & $1.15(2.76)$ & 0.68 & 0.82 \\
\hline 2 & cg11023668 & ILMN_1676893 & $A D C Y 3$ & $100.00 \%$ & Body & $-0.51(0.92)$ & 0.58 & 0.73 \\
\hline 2 & cg20995564 & ILMN_1688698 & ZEB2 & $100.00 \%$ & Body & $1.39(1.26)$ & 0.27 & 0.46 \\
\hline 3 & cg21945842 & ILMN_1670870 & ALCAM & $100.00 \%$ & TSS1500 & 3.25 (3.58) & 0.37 & 0.57 \\
\hline 5 & cg24805089 & ILMN_2357015 & GRK6 & $100.00 \%$ & Body & $-2.42(4.28)$ & 0.57 & 0.78 \\
\hline 5 & cg24805089 & ILMN_1681802 & GRK6 & $100.00 \%$ & Body & $0.68(4.37)$ & 0.88 & 0.97 \\
\hline 7 & cg21852842 & ILMN_2358069 & MADIL1 & $100.00 \%$ & Body & $3.14(1.73)$ & 0.07 & 0.19 \\
\hline 8 & cg18734877 & ILMN_1732318 & PTK2B & $100.00 \%$ & Body & $5.44(2.21)$ & 0.01 & 0.05 \\
\hline 8 & cg18734877 & ILMN_2330966 & PTK2B & $100.00 \%$ & Body & $3.51(2.18)$ & 0.11 & 0.23 \\
\hline 8 & cg18734877 & ILMN_1698849 & CHRNA2 & $82.64 \%$ & $<50 \mathrm{~kb}$ & $0.15(2.53)$ & 0.95 & 0.98 \\
\hline 8 & cg18734877 & ILMN_1709237 & EPHX2 & $100.00 \%$ & $<50 \mathrm{~kb}$ & $-2.03(2.19)$ & 0.35 & 0.57 \\
\hline 16 & cg07798295 & ILMN_1709439 & CHMP1A & $100.00 \%$ & Body & $-2.63(3.67)$ & 0.47 & 0.67 \\
\hline 19 & cg18608055 & ILMN_1808811 & SBNO2 & $100.00 \%$ & Body & $7.28(1.81)$ & $9.53 \times 10^{-5}$ & $6.48 \times 10^{-4}$ \\
\hline 19 & cg18608055 & ILMN_1734353 & GPX4 & $100.00 \%$ & $<50 \mathrm{~kb}$ & $-10.28(1.78)$ & $4.48 \times 10^{-8}$ & $7.62 \times 10^{-7}$ \\
\hline 19 & cg18608055 & ILMN_2378952 & GPX4 & $100.00 \%$ & $<50 \mathrm{~kb}$ & $-10.57(1.77)$ & $1.84 \times 10^{-8}$ & $6.26 \times 10^{-7}$ \\
\hline 19 & cg18608055 & ILMN_1811392 & HMHAI & $100.00 \%$ & $<50 \mathrm{~kb}$ & $9.28(1.79)$ & $7.40 \times 10^{-7}$ & $8.39 \times 10^{-6}$ \\
\hline 19 & cg18608055 & ILMN_3239240 & POLRZE & $100.00 \%$ & $<50 \mathrm{~kb}$ & $0.78(1.97)$ & 0.69 & 0.81 \\
\hline 19 & $\operatorname{cg} 26470501^{\mathrm{a}}$ & ILMN_1710514 & $B C L 3$ & $100.00 \%$ & Body & $-3.77(2.55)$ & 0.14 & 0.27 \\
\hline 20 & $\operatorname{cg} 24263062^{\mathrm{a}}$ & ILMN_3261292 & EBF4 & $90.97 \%$ & Body & $2.01(1.33)$ & 0.14 & 0.27 \\
\hline 20 & cg24263062 & ILMN_1712046 & CPXM1 & $66.67 \%$ & $<50 \mathrm{~kb}$ & $2.57(1.49)$ & 0.09 & 0.21 \\
\hline 20 & $\operatorname{cg} 05825244^{\mathrm{a}}$ & ILMN_3261292 & EBF4 & $90.97 \%$ & Body & $1.25(0.73)$ & 0.09 & 0.21 \\
\hline 20 & cg05825244 & ILMN_1712046 & CPXM1 & $66.67 \%$ & $<50 \mathrm{~kb}$ & $2.06(0.82)$ & 0.01 & 0.04 \\
\hline 20 & cg01523712 & ILMN_1746031 & RIMS4 & $59.44 \%$ & Body & $1.80(2.39)$ & 0.45 & 0.67 \\
\hline 22 & cg09349128 & ILMN_1782129 & ZBED4 & $100.00 \%$ & $<50 \mathrm{~kb}$ & $10.42(2.88)$ & $4.20 \times 10^{-4}$ & $2.04 \times 10^{-3}$ \\
\hline 22 & cg09349128 & ILMN_1743995 & ALG12 & $97.22 \%$ & $<50 \mathrm{~kb}$ & $-0.14(3.00)$ & 0.96 & 0.96 \\
\hline 22 & cg09349128 & ILMN_1748707 & CRELD2 & $100.00 \%$ & $<50 \mathrm{~kb}$ & $-0.20(2.97)$ & 0.95 & 1.00 \\
\hline 22 & cg09349128 & ILMN_1672034 & PIM3 & $48.95 \%$ & $<50 \mathrm{~kb}$ & $-5.22(3.86)$ & 0.18 & 0.33 \\
\hline 22 & cg09349128 & ILMN_1707748 & PIM3 & $100.00 \%$ & $<50 \mathrm{~kb}$ & $-12.08(2.76)$ & $2.34 \times 10^{-5}$ & $1.99 \times 10^{-4}$ \\
\hline 22 & cg09349128 & ILMN_1789781 & PIM3 & $88.11 \%$ & $<50 \mathrm{~kb}$ & $-7.22(3.04)$ & 0.02 & 0.06 \\
\hline
\end{tabular}

Methylation-expression correlations were calculated using linear regressions in which inverse normal transformed expression values were regressed on original methylation values adjusted for age and gender. The significant threshold of methylation-expression associations was set at FDR $<0.05$

a DNA methylation level of cg26470501 was reported to associated with expression of BCL3 gene; DNA methylation level of cg24263062 and cg05825244 was reported to positively associated with EBF4 gene in public database (FDR $<0.05)$ (https://www.genenetwork.nl/biosqtlbrowser/)

dose-response manner: The odds ratio according to per interquartile range increase of $\mathrm{Cu}$ was 1.29 (95\% CI 1.13, 1.46), and the median $\mathrm{Cu}$ concentration in the control group of this study was $963.4 \mu \mathrm{g} / \mathrm{L}$. Our study participants had a wide scope of $\mathrm{Cu}$ concentrations, ranging from 200 to $1600 \mu \mathrm{g} / \mathrm{L}$. The observed preference for $\mathrm{Cu}-$ associated hypomethylation was consistent with the findings of previous study that higher $\mathrm{Cu}$ was associated with a lower global DNA methylation profile of leukocytes
[22]. Kennedy et al. [23] also observed that hypomethylation is more common than hypermethylation among top CpGs associated with copper concentration. They also suggested that copper-associated DNA methylation patterns in placentae may mediate normal placenta and fetal development. However, they did not find a statistically significant association between copper status and methylation status at any single CpG. The DNA methylation alterations identified in the current study may provide 
Table 4 Adjusted odds ratios for the incident ACS according to quartiles of DNA methylation level

\begin{tabular}{|c|c|c|c|c|c|c|c|}
\hline & \multicolumn{4}{|c|}{ Quartiles of methylation level ${ }^{\mathrm{a}}$} & \multirow[t]{2}{*}{$p$-Trend ${ }^{b}$} & \multirow[t]{2}{*}{ Linear model ${ }^{c}$} & \multirow[t]{2}{*}{$p$-Linearity ${ }^{d}$} \\
\hline & Q1 & Q2 & Q3 & Q4 & & & \\
\hline cg20995564 & $<0.3834$ & $0.3834-0.4141$ & $0.4141-0.4473$ & $\geq 0.4473$ & & & \\
\hline$n$ (case/control) & $85 / 85$ & $88 / 82$ & $82 / 89$ & $86 / 85$ & & & \\
\hline Model $1^{\mathrm{e}}$ & 1.00 (ref) & $1.07(0.70,1.64)$ & $0.92(0.60,1.41)$ & $1.01(0.66,1.54)$ & 0.89 & $1.02(0.88,1.19)$ & 0.78 \\
\hline Model $2^{f}$ & 1.00 (ref) & $0.96(0.59,1.58)$ & $0.92(0.56,1.51)$ & $0.77(0.47,1.27)$ & 0.30 & $0.95(0.80,1.13)$ & 0.55 \\
\hline $\operatorname{cg} 18608055$ & $<0.4760$ & $0.4760-0.5140$ & $0.5140-0.5560$ & $\geq 0.5560$ & & & \\
\hline n (case/control) & $75 / 95$ & $92 / 79$ & $80 / 90$ & $94 / 77$ & & & \\
\hline Model $1^{\mathrm{e}}$ & 1.00 (ref) & $1.48(0.96,2.27)$ & $1.13(0.73,1.73)$ & $1.55(1.01,2.38)$ & 0.12 & $1.09(0.94,1.27)$ & 0.26 \\
\hline Model $2^{f}$ & 1.00 (ref) & $1.53(0.93,2.52)$ & $1.06(0.64,1.75)$ & $1.23(0.75,2.03)$ & 0.74 & $1.00(0.84,1.19)$ & 0.98 \\
\hline $\operatorname{cg} 26470501$ & $<0.3905$ & $0.3905-0.4170$ & $0.4170-0.4395$ & $\geq 0.4395$ & & & \\
\hline n (case/control) & $92 / 79$ & $82 / 88$ & $80 / 91$ & $87 / 83$ & & & \\
\hline Model $1^{\mathrm{e}}$ & 1.00 (ref) & $0.80(0.52,1.22)$ & $0.75(0.49,1.15)$ & $0.89(0.57,1.37)$ & 0.51 & $0.90(0.77,1.05)$ & 0.19 \\
\hline Model $2^{f}$ & 1.00 (ref) & $0.74(0.45,1.23)$ & $0.86(0.52,1.43)$ & $1.06(0.63,1.79)$ & 0.75 & $0.96(0.79,1.15)$ & 0.63 \\
\hline cg05825244 & $<0.4458$ & $0.4458-0.5636$ & $0.5636-0.6648$ & $\geq 0.6648$ & & & \\
\hline$n$ (case/control) & $74 / 97$ & $89 / 81$ & $86 / 85$ & $92 / 78$ & & & \\
\hline Model $1^{\mathrm{e}}$ & 1.00 (ref) & $1.45(0.95,2.23)$ & $1.34(0.87,2.06)$ & $1.58(1.02,2.44)$ & 0.06 & $1.17(1.00,1.37)$ & 0.05 \\
\hline Model $2^{f}$ & 1.00 (ref) & $1.45(0.88,2.39)$ & $1.40(0.85,2.31)$ & $1.78(1.07,2.98)$ & 0.04 & $1.23(1.02,1.48)$ & 0.03 \\
\hline
\end{tabular}

a DNA methylation level of CpGs was presented as relative level after normalization

b $P$ for trend across quartiles of $\mathrm{CpG}$ s were obtained by including the median of each quartile as a continuous variable in logistic regression models

c Odds ratios $(95 \% \mathrm{Cl})$ for incident ACS correspond to one-unit increase in inverse normal transformation of methylation level

d $P$ for linearity were obtained by including inverse normal transformation methylation values as continuous variable in linear regression models

e Model 1 was adjusted for age and sex in the unconditional logistic regression model

${ }^{f}$ Model 2 was additionally adjusted for body mass index, smoking status, drinking status, hypertension, hyperlipidemia, and diabetes in the unconditional logistic regression model

novel insights into the biological function of copper and the association of $\mathrm{Cu}$ with CVD.

Higher arsenic exposure was associated with increased methylation level at cg05825244 (chr20: 2730488) and cg24263062 (chr20: 2730191), both located in the gene body of EBF Family Member 4 (EBF4). These two loci were found to be strongly associated with increased gene expression of EBF4 in public database [35], and we also observed that cg05825244 was moderately associated with increased expression of its nearby gene CPXM1 in our gene expression profile data. We also found several other methylation loci on EBF4 gene were associated with Cu concentrations. EBF4 encodes transcription factor $\mathrm{COE} 4$, which has an essential regulatory function in neural development and B-cell maturation [38]. Interestingly, it has been suggested that EBF4 had a protein-protein interaction with APP, which has a Cu-binding domain that can reduce $\mathrm{Cu}^{2+}$ to $\mathrm{Cu}^{+}$with oxidative damage [39]. We observed that increased methylation level of cg05825244 related to higher $\mathrm{Cu}$ exposure was associated with lower HDL-C level and increased risk of ACS. Exposure to excess $\mathrm{Cu}$ has been demonstrated to initiate oxidative damage in several in vivo and in vitro studies, which may induce lipid peroxidation, endothelial dysfunction, and vascular injury $[8,9]$. Our results suggest that copper-associated DNA methylation alterations may mediate abnormal lipid metabolism and thus participate in the development of ACS. Nevertheless, the results from the current study do not infer causal directionality. It is necessary to conduct more research to explore the biological implications of these findings (Additional file 4).

The top hit from our study is cg20995564 (chr2: $145172035)$, located in the body of $Z E B 2$ gene. The protein encoded by $Z E B 2$ is a member of the Zfh1 family of two-handed zinc finger/homeodomain proteins. The related pathways of $Z E B 2$ are TGF-beta Receptor Signaling and MicroRNAs in cancer. $Z E B 2$ has been implicated to be associated with several diseases including MowatWilson syndrome and esophageal cancer [40]. Mutations in this gene have been associated with total cholesterol (TC) and LDL-C [41]. Furthermore, we found the methylation level of cg20995564 have been identified in an EWAS of CRP [42]. Plasma $\mathrm{Cu}$ has shown a strong positive correlation with CRP concentrations and inflammation [43]. It suggests that increased inflammation level associated with $\mathrm{Cu}$ could be mediated by methylation, 
but more research is warranted to verify the specific mechanism.

Higher $\mathrm{Cu}$ exposure was associated with decreased methylation level at the cg18608055 locus (chr19: 1130866) located in the body of $S B N O 2$ gene and cg26470501 locus located in the body of BCL3 gene (chr19: 45252955). These two loci were strongly associated with increased gene expression of $\mathrm{SBNO} 2$ and decreased gene expression of $B C L 3$, respectively. Of interest, the decreased methylation level of these two loci was also strongly associated with higher CRP concentrations and higher risk of inflammatory bowel disease (IBD) in previous EWAS studies [42, 44]. Consistently, we verified that the methylation alteration at cg26470501 was associated with CRP level. SBNO4 encodes the strawberry notch homolog 2 protein, which is involved in the transcriptional corepression of NF- $\mathrm{kB}$ in macrophages, as well as proinflammatory cascade [45]. $B C L 3$ is a proto-oncogene candidate gene with the function of transcriptional co-activation that activates through its association with NF-kB homodimers. The expression of $B C L 3$ gene can be induced by NF- $\mathrm{KB}$, which forms a part of the autoregulatory loop that controls the nuclear residence of p50 NF- $\mathrm{KB}$ [46]. The mutations in $B C L 3$ have been associated with HDL-C level, fasting insulin level and Alzheimer's disease (AD) [47]. Elevated $\mathrm{Cu}$ has been observed in cancer, IBD and AD patients in previous studies [48-50]. Taken together, these findings indicate that DNA methylation has the potential to explain the association of $\mathrm{Cu}$ with lipid metabolism, inflammatory response, and $\mathrm{Cu}$-related diseases.

Our top 500 sites included genes that were significantly enriched for insulin signaling pathway and type 2 diabetes mellitus pathway. Exposure to higher $\mathrm{Cu}$ level has primarily been reported to relate to a higher risk of diabetes [51]. Our findings provide evidence that these biological pathways of interest in humans may be perturbed by $\mathrm{Cu}$ associated differential DNA methylation alterations and further lead to diseases.

To the best of our knowledge, this was the first study to identify the significant CpGs associated with plasma $\mathrm{Cu}$ at genome-wide DNA methylation level. The major strengths of the present study are the relatively large sample size of the study and the availability of genome-wide methylation data. The combination of the epigenomewide methylation data with genome-wide expression data as well as gene enrichment analyses allowed us to evaluate potentially functional gene regulation associated with the differentially methylated loci. In addition, the prospective design of nested case-control study for ACS gave us the chance to investigate the associations of $\mathrm{Cu}$-related CpGs with future ACS. Further integration of these findings with clinical outcome data suggested for the first time that DNA methylation had a potential role as an intermediate biomarker for in the complex interplay between cooper, lipid metabolism, and ACS risk.

This study also has several potential limitations. First, this was an observational study measuring plasma $\mathrm{Cu}$ concentrations and DNA methylation level at the same time point. Therefore, the causality between the $\mathrm{Cu}$ concentrations and DNA methylation variations could not be determined. Further relevant longitudinal study and large Mendelian randomization studies are needed. Second, although we used the SmartSVA method and adjusted for major leukocyte compositions to control for the confounding effects of cell composition batch, potential cofounding still exists. Future studies of DNA methylation in specific cell type for different tissues may be able to solve this limitation. Third, although we adjusted for several confounders and used SmartSVA to remove significant unknown confounding effects in our study, we cannot rule out all the unmeasured or residual confounding. Fourth, the participants in our study are all Chinese adults, we did not validate the identified methylation signals in other populations; therefore, the generalization to other populations is limited. Fifth, the assay that we used to measure plasma copper did not distinguish between protein-bound copper and free copper forms. In the human body, $85 \%$ to $95 \%$ of the blood copper is covalently bound to the ceruloplasmin molecule, and another $5 \%$ to $15 \%$ is loosely bound to albumin and small molecules in the blood in the form of free copper [52]. Free copper is a harmful form that can produce reactive oxygen species and cause cell damage [53]. More DNA methylation studies focusing on free copper are needed in the future. Finally, although we have identified novel methylation loci for plasma copper, we were unable to investigate the exact functional mechanisms behind the observed methylation changes associated with $\mathrm{Cu}$ exposure, and the small number of identified differentially methylated loci may limit our clinical relevance. Despite these limitations, we believed that our findings provided evidence for potential mechanisms involving DNA methylation alterations that may partly explain the association of copper with ACS. Further studies are warranted to explore the biological implications of these findings.

\section{Conclusion}

In summary, we identified four novel DNA methylation sites related to $\mathrm{Cu}$ exposure, three of which were associated with corresponding gene expression level. In addition, we observed that $\mathrm{Cu}$-related DNA methylation alteration at cg05825244 was associated with increased risk of ACS, which may be attributed to abnormal lipid 
metabolism and inflammation. The findings from the current study may provide new insights regarding the epigenetic regulation mechanisms between copper and cardiovascular diseases and suggest potential targets for intervention or prevention of copper-related clinical consequences.

\section{Supplementary Information}

The online version contains supplementary material available at https://doi. org/10.1186/s13148-021-01004-w.

Additional file 1. Method S1: Details of the study population. Method S2: Covariate assessment. Method S3: Detailed processing methods for DNA methylation and gene expression.

Additional file 2. Table S1: Covariates used in associations of four copper-associated CpGs with incident ACS in the DFTJ panel. Table S2: Results from panel-specific analyses of plasma copper-associated DNA methylation, for probes with meta-analysis $p$-Value $<1 \times 10^{-5}$, sorted by chromosome. Table S3: Significantly enriched KEGG pathways $(F D R<0.05$ ) associated with genes annotated to the top $500 \mathrm{CpG}$ sites. Table S4: Metaanalysis of associations between four plasma copper-related CpGs (FDR $<0.05$ ) with major cardiovascular risk factors.

Additional file 3. Figure S1: The flowchart of the study. Figure S2: Distribution of plasma copper concentrations in five panels. Figure S3: Regional association plot of Cu meta-analysis results within and surrounding the EBF4 gene.

Additional file 4. This file presents a complete set of the meta-analysis results of the EWAS for plasma copper in this study.

\section{Abbreviations}

ACS: Acute coronary syndrome; AD: Alzheimer's disease; AMl: Acute myocardial infarction; BMI: Body mass index; CpGs: Cytosine-phosphoguanines; CRP: C-reactive protein; Cu: Copper; CVD: Cardiovascular disease; DBP: Diastolic blood pressure; DFTJ cohort: Dongfeng-Tongji cohort; DMC: Dongfeng Motor Corporation; DMRs: Differentially methylated regions; EWAS: Epigenomewide association study; FDR: False discovery rate; FG: Fasting glucose; HDL-C: High-density lipoprotein cholesterol; IBD: Inflammatory bowel disease; ICC: Intraclass correlation coefficient; ICP-MS: Inductively coupled plasma mass spectrometer; INT: Inverse normal transformed; KEGG: Kyoto Encyclopedia of Genes and Genomes; LDL-C: Low-density lipoprotein cholesterol; NSTEMI: Non-ST-segment elevation myocardial infarction; SBP: Systolic blood pressure; SVs: Surrogate variables; SY: Shiyan; TC: Total cholesterol; TG: Triglyceride; UA: Unstable angina; WHZH: Wuhan-Zhuhai.

\section{Acknowledgements}

The funder had no role in study design, data collection and analysis, decision to publish, or preparation of the manuscript. We thank all study participants, researchers, and students who participated in the present study.

\section{Authors' contributions}

PPL and QHW contributed to the statistical analysis and interpretation of the results and wrote the manuscript. PPL, QHW, YZZ, XYZ, KY, HJJ, XZL, and MZ contributed to the acquisition of data and researched the data. PPL, QHW, and TCW contributed to the study design. $\mathrm{KL}$, JJ, XMZ, MAH, HG, WHC, JY, LXC, and LML contributed to the discussion of the project. LML and TCW reviewed and edited the manuscript. TCW is the guarantor of this work and, as such, had full access to all the data in the study and takes responsibility for the integrity of the data and the accuracy of the data analysis. All authors read and approved the final manuscript.

\section{Funding}

This study was supported by the National Natural Scientific Foundation of China (81930092 and 91643202), the National Key Research and Development Program of China (2016YFC0900800), the Fundamental Research Funds for the
Central Universities (2019kfyXMBZ015), the 111 Project and the Program for Changjiang Scholars and Innovative Research Team in University to T.W.

\section{Ethics approval and consent to participate}

This research was performed under the supervision and approval of the Ethics and Human Subject Committees of Tongji Medical College. All participants agreed to participate in this study and signed the written informed consent.

\section{Consent for publication}

Not applicable.

\section{Competing interests}

All authors declare that they have no competing interests.

\section{Author details}

${ }^{1}$ Department of Occupational and Environmental Health, Key Laboratory of Environment and Health, Ministry of Education and State Key Laboratory of Environmental Health (Incubating), School of Public Health, Tongji Medical College, Huazhong University of Science and Technology, 13 Hangkong Rd., Wuhan 430030, Hubei, China. ${ }^{2}$ Suzhou Center for Disease Prevention and Control, Suzhou, China. ${ }^{3}$ Department of Cardiology, Union Hospital, Tongji Medical College, Huazhong University of Science and Technology, Wuhan, China. ${ }^{4}$ Department of Epidemiology, Harvard T.H. Chan School of Public Health, Boston, MA, USA. ${ }^{5}$ Department of Biostatistics, Harvard T.H. Chan School of Public Health, Boston, MA, USA.

Received: 20 September 2020 Accepted: 4 January 2021 Published online: 27 January 2021

\section{References}

1. Scheiber I, Dringen R, Mercer JF. Copper: effects of deficiency and overload. Met lons Life Sci. 2013;13:359-87. https://doi. org/10.1007/978-94-007-7500-8_11.

2. Ford ES. Serum copper concentration and coronary heart disease among US adults. Am J Epidemiol. 2000;151(12):1182-8. https://doi.org/10.1093/ oxfordjournals.aje.a010168.

3. Xiao Y, Yuan Y, Liu Y, Yu Y, Jia N, Zhou L, et al. Circulating multiple metals and incident stroke in Chinese adults. Stroke. 2019;50(7):1661-8. https:// doi.org/10.1161/STROKEAHA.119.025060.

4. Chowdhury R, Ramond A, O'Keeffe LM, Shahzad S, Kunutsor SK, Muka T, et al. Environmental toxic metal contaminants and risk of cardiovascular disease: systematic review and meta-analysis. BMJ. 2018;362:k3310. https ://doi.org/10.1136/bmj.k3310.

5. Chen A, Li G, Liu Y. Association between copper levels and myocardial infarction: a meta-analysis. Inhal Toxicol. 2015;27(5):237-46. https://doi. org/10.3109/08958378.2015.1030480.

6. Salonen JT, Salonen R, Korpela H, Suntioinen S, Tuomilehto J. Serum copper and the risk of acute myocardial infarction: a prospective population study in men in eastern Finland. Am J Epidemiol. 1991;134(3):268-76. https://doi.org/10.1093/oxfordjournals.aje.a116080.

7. Pereira TC, Campos MM, Bogo MR. Copper toxicology, oxidative stress and inflammation using zebrafish as experimental model. J Appl Toxicol. 2016;36(7):876-85. https://doi.org/10.1002/jat.3303.

8. Gaetke LM, Chow CK. Copper toxicity, oxidative stress, and antioxidant nutrients. Toxicology. 2003;189(1-2):147-63. https://doi.org/10.1016/ s0300-483x(03)00159-8.

9. Kitazawa M, Hsu HW, Medeiros R. Copper exposure perturbs brain inflammatory responses and impairs clearance of amyloid-beta. Toxicol Sci. 2016;152(1):194-204. https://doi.org/10.1093/toxsci/kfw081.

10. Maiorino M, Zamburlini A, Roveri A, Ursini F. Copper-induced lipid peroxidation in liposomes, micelles, and LDL: which is the role of vitamin E? Free Radic Biol Med. 1995;18(1):67-74. https://doi.org/10.1016/08915849(94)00103-q.

11. Kang YJ. Copper and homocysteine in cardiovascular diseases. Pharmacol Ther. 2011;129(3):321-31. https://doi.org/10.1016/j.pharmthera .2010.11.004. 
12. Moore LD, Le T, Fan G. DNA methylation and its basic function. Neuropsychopharmacology. 2013;38(1):23-38. https://doi.org/10.1038/ npp.2012.112.

13. Robertson KD. DNA methylation and human disease. Nat Rev Genet. 2005;6(8):597-610. https://doi.org/10.1038/nrg1655.

14. Li J, Zhu X, Yu K, Jiang H, Zhang Y, Deng S, et al. Genome-wide analysis of DNA methylation and acute coronary syndrome. Circ Res. 2017;120(11):1754-67. https://doi.org/10.1161/CIRCRESAHA.116.310324.

15. Klutstein M, Nejman D, Greenfield R, Cedar H. DNA methylation in cancer and aging. Cancer Res. 2016;76(12):3446-50. https://doi. org/10.1158/0008-5472.CAN-15-3278.

16. Chambers JC, Loh M, Lehne B, Drong A, Kriebel J, Motta V, et al. Epigenome-wide association of DNA methylation markers in peripheral blood from Indian Asians and Europeans with incident type 2 diabetes: a nested case-control study. Lancet Diabetes Endocrinol. 2015;3(7):526-34. https:// doi.org/10.1016/S2213-8587(15)00127-8.

17. Berson A, Nativio R, Berger SL, Bonini NM. Epigenetic regulation in neurodegenerative diseases. Trends Neurosci. 2018;41(9):587-98. https://doi. org/10.1016/j.tins.2018.05.005

18. Everson TM, Punshon T, Jackso BP, Hao K, Lambertini L, Chen J, et al. Cadmium-associated differential methylation throughout the placental genome: epigenome-wide association study of two U.S, birth cohorts. Environ Health Perspect. 2018;126(1):017010. https://doi.org/10.1289/ EHP2192.

19. Maccani JZ, Koestler DC, Lester B, Houseman EA, Armstrong DA, Kelsey $K T$, et al. Placental DNA methylation related to both infant toenail mercury and adverse neurobehavioral outcomes. Environ Health Perspect. 2015;123(7):723-9. https://doi.org/10.1289/ehp.1408561.

20. Ren X, McHale CM, Skibola CF, Smith AH, Smith MT, Zhang L. An emerging role for epigenetic dysregulation in arsenic toxicity and carcinogenesis. Environ Health Perspect. 2011;119(1):11-9. https://doi.org/10.1289/ ehp.1002114

21. Bihaqi SW. Early life exposure to lead $(\mathrm{Pb})$ and changes in DNA methylation: relevance to Alzheimer's disease. Rev Environ Health. 2019;34(2):187-95. https://doi.org/10.1515/reveh-2018-0076.

22. Passador J, Toffoli LV, Fernandes KB, Neves-Souza RD, Pelosi GG, Gomes MV. Dietary ingestion of calories and micronutrients modulates the DNA methylation profile of leukocytes from older individuals. J Nutr Health Aging. 2018;22(10):1281-5. https://doi.org/10.1007/s12603-018-1085-6.

23. Kennedy E, Everson TM, Punshon T, Jackson BP, Hao K, Lambertini L, et al. Copper associates with differential methylation in placentae from two US birth cohorts. Epigenetics. 2020;15(3):215-30. https://doi. org/10.1080/15592294.2019.1661211.

24. Li J, Zhu X, Yu K, Jiang H, Zhang Y, Wang B, et al. Exposure to polycyclic aromatic hydrocarbons and accelerated DNA methylation aging. Environ Health Perspect. 2018;126(6):067005. https://doi.org/10.1289/EHP2773.

25. Zhu X, Li J, Deng S, Yu K, Liu X, Deng Q, et al. Genome-wide analysis of DNA methylation and cigarette smoking in a Chinese population. Environ Health Perspect. 2016;124(7):966-73. https://doi.org/10.1289/ehp.15098 34.

26. Wang F, Zhu J, Yao P, Li X, He M, Liu Y, et al. Cohort profile: the DongfengTongji cohort study of retired workers. Int J Epidemiol. 2013;42(3):731-40. https://doi.org/10.1093/ije/dys053.

27. O'Connor RE, Bossaert L, Arntz HR, Brooks SC, Diercks D, Feitosa-Filho G, et al. Part 9: acute coronary syndromes: 2010 international consensus on cardiopulmonary resuscitation and emergency cardiovascular care science with treatment recommendations. Circulation. 2010;122(16 Suppl 2):S422-65. https://doi.org/10.1161/CIRCULATIONAHA.110.985549.

28. O'Gara PT, Kushner FG, Ascheim DD, Casey DE, Chung MK, de Lemos JA, et al. 2013 ACCF/AHA guideline for the management of ST-elevation myocardial infarction: a report of the American College of Cardiology Foundation/American Heart Association Task Force on Practice Guidelines. Circulation. 2013;127(4):529-55. https://doi.org/10.1161/CIR.0b013 e3182742c84

29. Bassand JP, Hamm CW, Ardissino D, Boersma E, Budaj A, Fernández-Avilés $F$, et al. Guidelines for the diagnosis and treatment of non-ST-segment elevation acute coronary syndromes. Eur Heart J. 2007;28(13):1598-660. https://doi.org/10.1093/eurheartj/ehm161.

30. Wright RS, Anderson JL, Adams CD, Bridges CR, Casey DE, Ettinger SM, et al. 2011 ACCF/AHA focused update incorporated into the ACC/AHA 2007 Guidelines for the Management of Patients with Unstable Angina/
Non-ST-Elevation Myocardial Infarction: a report of the American College of Cardiology Foundation/American Heart Association Task Force on Practice Guidelines developed in collaboration with the American Academy of Family Physicians, Society for Cardiovascular Angiography and Interventions, and the Society of Thoracic Surgeons. J Am Coll Cardiol. 2011;57(19):e215-367. https://doi.org/10.1016/j.jacc.2011.02.011.

31. Song $Y$, Hou J, Huang $X$, Zhang $X$, Tan A, Rong Y, et al. The Wuhan-Zhuhai (WHZH) cohort study of environmental air particulate matter and the pathogenesis of cardiopulmonary diseases: study design, methods and baseline characteristics of the cohort. BMC Public Health. 2014;14:994. https://doi.org/10.1186/1471-2458-14-994.

32. Yuan $Y$, Xiao Y, Feng W, Liu Y, Yu Y, Zhou L, et al. Plasma metal concentrations and incident coronary heart disease in Chinese adults: the Dongfeng-Tongji cohort. Environ Health Perspect. 2017;125(10):107007. https://doi.org/10.1289/EHP1521.

33. Chen J, Behnam E, Huang J, Moffatt MF, Schaid DJ, Liang L, et al. Fast and robust adjustment of cell mixtures in epigenome-wide association studies with SmartSVA. BMC Genom. 2017;18(1):413. https://doi.org/10.1186/ s12864-017-3808-1.

34. Martin TC, Yet I, Tsai PC, Bell JT. coMET: visualisation of regional epigenome-wide association scan results and DNA co-methylation patterns. BMC Bioinform. 2015;16(1):131. https://doi.org/10.1186/s1285 9-015-0568-2.

35. Zhernakova DV, Deelen $P$, Vermaat $M$, van Iterson $M$, van Galen $M$, Arindrarto $W$, et al. Identification of context-dependent expression quantitative trait loci in whole blood. Nat Genet. 2017;49(1):139-45. https://doi.org/10.1038/ng.3737.

36. Subramanian A, Tamayo P, Mootha VK, Mukherjee S, Ebert BL, Gillette MA, et al. Gene set enrichment analysis: a knowledge-based approach for interpreting genome-wide expression profiles. PNAS. 2005;102(43):15545-50. https://doi.org/10.1073/pnas.0506580102.

37. Ma J, Betts NM. Zinc and copper intakes and their major food sources for older adults in the 1994-96 continuing survey of food intakes by individuals (CSFII). J Nutr. 2000;130(11):2838-43. https://doi. org/10.1093/jn/130.11.2838.

38. Wang SS, Betz AG, Reed RR. Cloning of a novel Olf-1/EBF-like gene, $\mathrm{O} / \mathrm{E}-4$, by degenerate oligo-based direct selection. Mol Cell Neurosci. 2002;20(3):404-14. https://doi.org/10.1006/mcne.2002.1138.

39. Oláh J, Vincze O, Virók D, Simon D, Bozsó Z, Tõkési N, et al. Interactions of pathological hallmark proteins: tubulin polymerization promoting protein/p25, beta-amyloid, and alpha-synuclein. J Biol Chem. 2011;286(39):34088-100. https://doi.org/10.1074/jbc.M111.243907.

40. Ivanovski I, Djuric O, Caraffi SG, Santodirocco D, Pollazzon M, Rosato S, et al. Phenotype and genotype of 87 patients with Mowat-Wilson syndrome and recommendations for care. Genet Med. 2018;20(9):965-75. https://doi.org/10.1038/gim.2017.221.

41. Sharma A, Bandyopadhayaya S, Chowdhury K, Sharma T, Maheshwari $R$, Das A, et al. Metformin exhibited anticancer activity by lowering cellular cholesterol content in breast cancer cells. PLOS ONE. 2019;14(1):e0209435. https://doi.org/10.1371/journal.pone.0209435.

42. Ligthart S, Marzi C, Aslibekyan S, Mendelson MM, Conneely KN, Tanaka $\mathrm{T}$, et al. DNA methylation signatures of chronic low-grade inflammation are associated with complex diseases. Genome Biol. 2016;17(1):255. https://doi.org/10.1186/s13059-016-1119-5.

43. Yuan Y, Long P, Liu K, Xiao Y, He S, Li J, et al. Multiple plasma metals, genetic risk and serum C-reactive protein: a metal-metal and gene-metal interaction study. Redox Biol. 2020;29:101404. https://doi. org/10.1016/j.redox.2019.101404.

44. Ventham NT, Kennedy NA, Adams AT, Kalla R, Heath S, O'Leary KR, et al. Integrative epigenome-wide analysis demonstrates that DNA methylation may mediate genetic risk in inflammatory bowel disease. Nat Commun. 2016;7:13507. https://doi.org/10.1038/ncomms13507.

45. Kasmi KC, Smith AM, Williams L, Neale G, Panopoulos AD, Watowich SS, et al. Cutting edge: a transcriptional repressor and corepressor induced by the STAT3-regulated anti-inflammatory signaling pathway. J Immunol. 2007;179(11):7215-9. https://doi.org/10.4049/jimmu nol.179.11.7215.

46. Puccio I, Khan S, Butt A, Graham D, Sehgal V, Patel D, et al. Immunohistochemical assessment of Survivin and Bcl3 expression as potential biomarkers for NF-KB activation in the Barrett 
metaplasia-dysplasia-adenocarcinoma sequence. Int J Exp Pathol. 2018;99(1):10-4. https://doi.org/10.1111/iep.12260.

47. Zhu Z, Lin Y, Li X, Driver JA, Liang L. Shared genetic architecture between metabolic traits and Alzheimer's disease: a large-scale genome-wide cross-trait analysis. Hum Genet. 2019;138(3):271-85. https://doi.org/10.1007/s00439-019-01988-9.

48. Zhang $X$, Yang Q. Association between serum copper levels and lung cancer risk: a meta-analysis. J Int Med Res. 2018;46(12):4863-73. https ://doi.org/10.1177/0300060518798507.

49. Ojuawo A, Keith L. The serum concentrations of zinc, copper and selenium in children with inflammatory bowel disease. Cent Afr J Med. 2002;48(9-10):116-9.

50. Sensi SL, Granzotto A, Siotto M, Squitti R. Copper and zinc dysregulation in Alzheimer's disease. Trends Pharmacol Sci. 2018;39(12):1049-63. https://doi.org/10.1016/j.tips.2018.10.001.

51. Qiu Q, Zhang F, Zhu W, Wu J, Liang M. Copper in diabetes mellitus: a meta-analysis and systematic review of plasma and serum studies.
Biol Trace Elem Res. 2017;177(1):53-63. https://doi.org/10.1007/s1201 1-016-0877-y.

52. Brewen GJ. The risks of free copper in the body and the development of useful anticopper drugs. Curr Opin Clin Nutr Metab Care. 2008;11(6):72732. https://doi.org/10.1097/MCO.0b013e328314b678.

53. Brewer GJ, Askari F, Dick RB, Sitterly J, Fink JK, Carlson M, et al. Treatment of Wilson's disease with tetrathiomolybdate: $\mathrm{V}$. control of free copper by tetrathiomolybdate and a comparison with trientine. Transl Res. 2009;154(2):70-7. https://doi.org/10.1016/j.trsl.2009.05.002.

\section{Publisher's Note}

Springer Nature remains neutral with regard to jurisdictional claims in published maps and institutional affiliations.
Ready to submit your research? Choose BMC and benefit from:

- fast, convenient online submission

- thorough peer review by experienced researchers in your field

- rapid publication on acceptance

- support for research data, including large and complex data types

- gold Open Access which fosters wider collaboration and increased citations

- maximum visibility for your research: over $100 \mathrm{M}$ website views per year

At BMC, research is always in progress.

Learn more biomedcentral.com/submissions 